\title{
Article \\ Link between Genotype and Multi-Organ Iron and Complications in Children with Transfusion-Dependent Thalassemia
}

\author{
Antonella Meloni ${ }^{1,2}$ (D), Laura Pistoia ${ }^{1}$ (D), Paolo Ricchi ${ }^{3}\left(\mathbb{D}\right.$, Maria Caterina Putti ${ }^{4}$, Maria Rita Gamberini ${ }^{5}$, \\ Liana Cuccia ${ }^{6}$, Giuseppe Messina ${ }^{7}$, Francesco Massei ${ }^{8}$, Elena Facchini ${ }^{9}$, Riccardo Righi ${ }^{10}$, Stefania Renne ${ }^{11}$, \\ Giuseppe Peritore $^{12}$, Vincenzo Positano ${ }^{1,2}$ a and Filippo Cademartiri ${ }^{1, *}$ (D)
}

Citation: Meloni, A.; Pistoia, L.; Ricchi, P.; Putti, M.C.; Gamberini, M.R.; Cuccia, L.; Messina, G.; Massei, F.; Facchini, E.; Righi, R.; et al. Link between Genotype and Multi-Organ Iron and Complications in Children with Transfusion-Dependent

Thalassemia. J. Pers. Med. 2022, 12, 400. https://doi.org/10.3390/ jpm12030400

Academic Editors: Adriana Ceci and Petros Kountouris

Received: 26 January 2022

Accepted: 3 March 2022

Published: 4 March 2022

Publisher's Note: MDPI stays neutral with regard to jurisdictional claims in published maps and institutional affiliations.

Copyright: (C) 2022 by the authors. Licensee MDPI, Basel, Switzerland. This article is an open access article distributed under the terms and conditions of the Creative Commons Attribution (CC BY) license (https:// creativecommons.org/licenses/by/ $4.0 /)$.
1 Department of Radiology, Fondazione G. Monasterio CNR-Regione Toscana, 56124 Pisa, Italy; antonella.meloni@ftgm.it (A.M.); laura.pistoia@ftgm.it (L.P.); positano@ftgm.it (V.P.)

2 U.O.C. Bioingegneria, Fondazione G. Monasterio CNR-Regione Toscana, 56124 Pisa, Italy

3 U.O.S.D. Malattie Rare del Globulo Rosso, Azienda Ospedaliera di Rilievo Nazionale "A. Cardarelli", 80131 Napoli, Italy; pabloricchi@libero.it

4 Dipartimento della Salute della Donna e del Bambino, Clinica di Emato-Oncologia Pediatrica, Azienda Ospedaliero-Università di Padova, 35128 Padova, Italy; mariacaterina.putti@unipd.it

5 Unità Operativa di Day Hospital della Talassemia e delle Emoglobinopatie, Dipartimento della Riproduzione e dell'Accrescimento, Azienda Ospedaliero-Universitaria "S. Anna", 44124 Cona, Italy; m.gamberini@ospfe.it

6 U.O.C. Ematologia con Talassemia, ARNAS Civico "Benfratelli-Di Cristina", 90134 Palermo, Italy; liana.cuccia@arnascivico.it

7 Centro Microcitemie, Grande Ospedale Metropolitano “Bianchi-Melacrino-Morelli”, 89100 Reggio Calabria, Italy; gspmessina@virgilio.it

8 Unità Operativa Oncoematologia Pediatrica, Azienda Ospedaliero Universitaria Pisana, 56126 Pisa, Italy; f.massei@med.unipi.it

9 Unità Operativa di Pediatria-Prof A Pession Programma di Oncologia, Ematologia e Trapianto Azienda Ospedaliero-Universitaria di Bologna-Policlinico "S. Orsola-Malpighi”, 40138 Bologna, Italy; elena.facchini@aosp.bo.it

10 Diagnostica per Immagini e Radiologia Interventistica, Ospedale del Delta, 44023 Lagosanto, Italy; riccardo.righi@ausl.fe.it

11 Struttura Complessa di Cardiologia-UTIC, Presidio Ospedaliero "Giovanni Paolo II", 88046 Lamezia Terme, Italy; stefania.renne@virgilio.it

12 U.O.C. di Radiologia, ARNAS Civico "Benfratelli-Di Cristina”, 90134 Palermo, Italy; giuseppe.peritore@hotmail.it

* Correspondence: fcademartiri@ftgm.it; Tel.: +39-050-3152817

Abstract: We evaluated the impact of the genotype on hepatic, pancreatic and myocardial iron content, and on hepatic, cardiac and endocrine complications in children with transfusion-dependent $\beta$-thalassemia ( $\beta$-TDT). We considered $68 \beta$-TDT patients (11.98 \pm 3.67 years, $51.5 \%$ females) consecutively enrolled in the Extension-Myocardial Iron Overload in Thalassemia network. Iron overload was quantified by $\mathrm{T}^{*}$ technique and biventricular function by cine images. Replacement myocardial fibrosis was evaluated by late gadolinium enhancement technique. Three groups of patients were identified: homozygous $\beta+(\mathrm{N}=19)$, compound heterozygous $\beta 0 \beta+(\mathrm{N}=24)$, and homozygous $\beta 0(\mathrm{~N}=25)$. The homozygous $\beta 0$ group showed significantly lower global heart and pancreas $\mathrm{T} 2{ }^{*}$ values than the homozygous $\beta+$ group. Compared to patients with homozygous $\beta+$ genotype, $\beta 0 \beta+$ as well as $\beta 0 \beta 0$ patients were more likely to have pancreatic iron overload (odds ratio $=6.53$ and 10.08 , respectively). No difference was detected in biventricular function parameters and frequency of replacement fibrosis. No patient had cirrhosis/fibrosis, diabetes or heart failure, and the frequency of endocrinopathies was comparable among the groups. In pediatric $\beta$-TDT patients, there is an association between genotype and cardiac and pancreatic iron overload. The knowledge of patients genotype can be valuable in predicting some patients' phenotypic features and in helping the clinical management of $\beta$-TDT patients.

Keywords: transfusion-dependent thalassemia; genotype; iron overload; complications 


\section{Introduction}

Beta-thalassemia is a genetic blood disease with a high incidence in the Mediterranean basin, Middle East, Indian subcontinent, Central Asia, and Far East [1]. However, due to migration, international job opportunities and intermarriages, thalassemia has become a global health problem. Beta-thalassemia is characterized by a wide spectrum of clinical manifestations and laboratory findings, and the disease phenotype largely depends on the underlying mutations of the $\beta$-globin gene [2]. More than 200 different mutations that affect the $\beta$-globin gene have been identified and their frequency varies significantly among countries or even in different regions of a single country [3]. Globally, in the Mediterranean Region the commonest mutations are CD39, IVS-1,110, IVS-1,1, IVS-1,6, IVS-2,745, IVS-2,1, and CD8, while CD41/42, IVS, 1-5, CD17, -28, COD8/9, IVS,2-654, and IVS-1,1 are the most prevalent mutations in the Asian Region [1]. These mutations cause a reduced $(\beta+)$ or absent $(\beta 0)$ production of the $\beta$-globin chain, with relative excess of $\alpha$-chains. The imbalance in the production of $\alpha$ - and $\beta$-globin chains results in ineffective erythropoiesis and peripheral red cell hemolysis, with consequent anemia [4]. However, the correlation between genotype and phenotype is complex, because other secondary/tertiary modifiers and environmental factors interact with the different allelic variants [2] and modulate the complex pathophysiology of $\beta$-thalassemia.

Based on the clinical severity and transfusion requirement, thalassemia can be classified into two main groups: transfusion-dependent thalassemia (TDT) and non-transfusiondependent thalassemia (NTDT). TDT is the most severe clinical form of $\beta$-thalassemia, and its current treatment consists of regular transfusions (every 2-5 weeks) to maintain pre-transfusion hemoglobin levels above 9-10.5 g/dL [5]. Chronic transfusions are not risk-free and iron overload represents the main drawback. As the human body lacks an active mechanism to excrete excess iron, a progressive accumulation of body iron easily occurs as a result of long-term transfusions [6,7]. Iron overload is cytotoxic and induces organ damage and failure in the liver, heart, pancreas, thyroid, and the central nervous system [8]. The introduction of the chelation therapy has led to a decrease of the iron burden, significantly prolonging the survival of the patients [9]. Moreover, the deployment of the $\mathrm{T}^{*}$ magnetic resonance imaging (MRI) technique for the noninvasive quantification of organ-specific iron overload has offered the possibility to design tailor-made chelation therapies meeting the individual patient's needs $[10,11]$, further improving the prognosis $[12,13]$. However, hepatic, cardiovascular and endocrine complications still occur $[13,14]$. The underlying genetic defect in thalassemia is an important factor in the development of these complications because the homozygous $\beta 0$ genotype state demands more red cells consumption and a greater rate of iron overloading [15,16].

A superior understanding of organ damage can be achieved by a comprehensive assessment of the children with TDT, representing the ideal population to study the initial stage of iron loading and the onset of its complications.

The aim of the present study was to evaluate the impact of the genotype on hepatic, pancreatic and myocardial iron content, and on hepatic, cardiac and endocrine complications in children with transfusion-dependent $\beta$-thalassemia.

\section{Materials and Methods}

\subsection{Study Population}

From the 1727 patients with hemoglobinopathies enrolled in the E-MIOT (ExtensionMyocardial Iron Overload in Thalassemia) Network, we retrospectively selected 68 pediatric (age $<18$ years) TDT patients who had undergone at least one MRI scan. We excluded the patients with $\mathrm{Hb}$ Lepore either in heterozygosis or in homozygosis and those with alfa abnormalities.

The E-MIOT Network is constituted by 66 thalassemia centres and 11 MRI sites where MR exams are performed using standardized and validated procedures $[17,18]$. All centers are linked by a web-based database configured to collect and share patients' history, clinical and diagnostic data [19]. 
All patients were regularly transfused to maintain a pre-transfusion hemoglobin concentration above 9-10 g/dL. MRI scanning was performed within one week before regular scheduled blood transfusion.

This study complied with the Declaration of Helsinki and was approved by the institutional ethic committees. Parents gave their informed consent for all patients.

\subsection{MRI}

MRI exams were performed on conventional clinical $1.5 \mathrm{~T}$ scanners of three main vendors (GE Healthcare, Philips Healthcare, Siemens Healthineers), equipped with a phased-array receiver surface coil.

For iron overload assessment, a mid-transverse hepatic slice [20], five or more axial slices including the whole pancreas [21], and basal, medium and apical short-axis views of the left ventricle (LV) $[22,23]$ were acquired by $\mathrm{T}^{*}$ gradient-echo multi-echo sequences. T2* image analysis was performed using a custom-written, previously validated software (HIPPO MIOT ${ }^{\circledR}$, V2.0, Consiglio Nazionale delle Ricerche and Fondazione Toscana Gabriele Monasterio, Pisa, Italy) [24]. Hepatic T2* values were calculated in a circular region of interest (ROI) of standard dimension [25] and were converted into liver iron concentration (LIC) using the Wood's calibration curve [26,27]. Three small ROIs were manually defined over pancreatic head, body and tail, taking care to avoid large blood vessels or ducts and areas involved in susceptibility artefacts from gastric or colic intraluminal gas [28]. Global pancreatic $\mathrm{T}^{*}$ value was calculated as the mean of $\mathrm{T} 2^{*}$ values from the three regions. The software provided the $\mathrm{T}^{*}$ value on each of the 16 segments of the $\mathrm{LV}$, according to the standard AHA/ACC model [29]. The global heart $\mathrm{T}^{*}$ value was obtained by averaging all segmental T2* values.

Steady-state free precession (SSFP) cine images were acquired in sequential 8-mm short-axis slices (gap $0 \mathrm{~mm}$ ) from the atrio-ventricular ring to the apex to quantify biventricular function parameters in a standard way [30]. The inter-center variability had been previously reported [31]. Left and right atrial areas were measured from the 4-chamber view projection in the ventricular end-systolic phase.

To detect the presence of replacement myocardial fibrosis, late gadolinium enhancement (LGE) short-axis and vertical, horizontal, and oblique long-axis images were acquired 10-18 min after Gadobutrol (Gadovist ${ }^{\circledR}$; Bayer; Berlin, Germany) intravenous administration at the standard dose of $0.2 \mathrm{mmol} / \mathrm{kg}$ using a fast gradient-echo inversion recovery sequence. The use of Gadobutrol has been demonstrated to be safe in patients with hemoglobinopathies [32]. LGE was considered present when visualized in two different views [33].

\subsection{Biochemical Assays}

All biochemical investigations were performed using commercially available kits at the laboratories of thalassemia centres where the patients were treated.

Genotyping was done using DNA sequencing techniques. Genomic DNA was extracted from peripheral blood leucocytes using the salting-out method [34]. All coding and noncoding regions of the $\beta$-globin gene were amplified by polymerase chain reaction (PCR) in different fragments. The PCR conditions were different, depending on the specific protocol adopted by the laboratory of thalassemia centre. B-thalassemia mutations were identified by reverse hybridization assay ( $\beta$-globin strip assay, Nuclear Laser, Vienna Lab, Austria).

The patients were monitored for glucose dysregulation according to the TIF guidelines [5], recommending an annual oral glucose tolerance test (OGTT) screening starting at age 10. Venous plasma glucose was measured fasting and $2 \mathrm{~h}$ after and oral glucose load (dose of $1.75 \mathrm{~g} / \mathrm{kg}$, with a maximum of $75 \mathrm{~g}$ ). 


\subsection{Diagnostic Criteria}

The compliance was collected by the investigators of each thalassemia center and based on the correspondence between the patient's actual dosing and the prescribed regimen, it was defined as excellent $(>80 \%)$, good $(60-80 \%)$ or insufficient $(<60 \%)$.

An MRI LIC $\geq 3 \mathrm{mg} / \mathrm{g} / \mathrm{dw}$ was considered indicative of a significant iron load [35]. It was previously determined that $26 \mathrm{~ms}$ is the lowest threshold of a normal global pancreas $\mathrm{T}^{*}$ value [21]. A T2* measurement of $20 \mathrm{~ms}$ was taken as a "conservative" normal value for segmental and global values [24,36,37].

Liver fibrosis was diagnosed if the liver stiffness assessed by transient elastography was $>7.0 \mathrm{kPa}$, while a liver stiffness $>12.5 \mathrm{kPa}$ was indicative of cirrhosis.

Diabetes mellitus (DM) was defined by fasting plasma glucose $\geq 126 \mathrm{mg} / \mathrm{dL}$ or $2-\mathrm{h}$ plasma glucose $\geq 200 \mathrm{mg} / \mathrm{dL}$ during an OGTT, or a random plasma glucose $\geq 200 \mathrm{mg} / \mathrm{dL}$ with classic symptoms of hyperglycemia or hyperglycemic crisis [38].

Hypogonadotropic hypogonadism was defined as luteinizing hormone (LH) and follicle stimulating hormone (FSH) levels below $2 \mathrm{IU} / \mathrm{L}$, with an estradiol concentration of below $20 \mathrm{pg} / \mathrm{mL}$ in girls or a testosterone concentration of below $3 \mathrm{ng} / \mathrm{mL}$ in boys. Hypogonadism was detected in females by the absence of breast development and in males by the absence of testicular enlargement $(<4 \mathrm{~mL})$ by the age of 16 years [39].

Hypothyroidism was defined as a high serum TSH concentration with normal or reduced free thyroxine levels (primary form) or normal or low serum TSH concentration with reduced free thyroxine levels (central form) [40].

Hypoparathyroidism was defined as low serum calcium concentration, increased serum phosphate, low serum parathyroid hormone or, if normal, inappropriate for the calcium level [41].

Diagnosis of growth hormone $(\mathrm{GH})$ deficiency required integration of growth criteria, medical history, laboratory tests (measurements of insulin-like growth factor 1 and insulinlike growth factor binding protein type 3 levels and provocative testing), and imaging studies [42].

Heart failure (HF) was identified based on symptoms and signs, according to the AHA/ACC guidelines [43]. Arrhythmias were diagnosed and classified according to the AHA/ACC guidelines [44].

\subsection{Statistical Analysis}

All data were analyzed using the SPSS v27.0 statistical package.

Continuous variables were described as mean \pm standard deviation (SD) and categorical variables were expressed as frequencies and percentages.

The normality of distribution of the parameters was assessed by using the KolmogorovSmirnov test.

For continuous values with normal distribution, comparisons among groups were made by one-way ANOVA. Kruskal-Wallis test was applied for continuous values with no normal distribution. The $\chi 2$ test was used for the comparison of non-continuous variables. Bonferroni post-hoc test was used for multiple comparisons between pairs of groups.

Correlation analysis was performed using Pearson's test or Spearman's test where appropriate.

Odds ratios (OR) and 95\% confidence intervals (CI) were calculated by using logistic regression.

In all tests, a two-tailed probability value of 0.05 was considered statistically significant

\section{Results}

\subsection{Patients' Characteristics}

All patients were white and 35 (51.5\%) were females. Mean age was $11.98 \pm 3.67$ years (range: 4-18 years).

Thirty-three different genotypes were recorded and the commonest were homozygous CD39, CD39/IVS-1,110, and homozygous IVS-1,110 (Table 1). 
Table 1. Frequency of different genotypes (based on type of mutation) in our pediatric TDT patients.

\begin{tabular}{|c|c|c|c|c|}
\hline Genotype & HGVS Nomenclature & Type & Cases (N) & Frequency $(\%)$ \\
\hline CD39/CD39 & HBB:c.118C > T/HBB:c.118C > T & $\beta 0 \beta 0$ & 11 & 16.2 \\
\hline CD39/IVS-1,110 & HBB:c.118C > T/HBB:c.93-21G > A & $\beta 0 \beta+$ & 7 & 10.3 \\
\hline IVS-1,110/IVS-1,110 & HBB:c.93-21G > A/HBB:c.93-21G > A & $\beta+\beta+$ & 6 & 8.8 \\
\hline IVS-1,110/IVS-2,745 & HBB:c.93-21G > A/HBB:c.316-106C > G & $\beta+\beta+$ & 4 & 5.9 \\
\hline CD5/CD5 & HBB:c.17_18delCT/HBB:c.17_18delCT & $\beta 0 \beta 0$ & 3 & 4.4 \\
\hline CD39/IVS-1,1 & HBB:c.118C > T/HBB:c. $92+1 \mathrm{G}>\mathrm{A}$ & $\beta 0 \beta 0$ & 3 & 4.4 \\
\hline IVS-1,6/IVS-1,110 & HBB:c.92 + 6T > C/HBB:c.93-21G > A & $\beta+\beta+$ & 3 & 4.4 \\
\hline CD39/IVS-1,6 & HBB:c. $118 \mathrm{C}>\mathrm{T} / \mathrm{HBB}: \mathrm{c} .92+6 \mathrm{~T}>\mathrm{C}$ & $\beta 0 \beta+$ & 3 & 4.4 \\
\hline $\mathrm{CD} 6 /-87$ & HBB:c.20delA/HBB:c.-137C > G & $\beta 0 \beta+$ & 2 & 2.9 \\
\hline CD39/IVS-2,1 & HBB:c.118C > T/HBB:c. $315+1 \mathrm{G}>\mathrm{A}$ & $\beta 0 \beta 0$ & 2 & 2.9 \\
\hline IVS-1,6/IVS-1,6 & HBB:c. $92+6 \mathrm{~T}>$ C $/$ HBB:c. $92+6 \mathrm{~T}>\mathrm{C}$ & $\beta+\beta+$ & 2 & 2.9 \\
\hline IVS-2,1/IVS-1,110 & HBB:c.315 + 1G > A/HBB:c.93-21G > A & $\beta 0 \beta+$ & 2 & 2.9 \\
\hline Others & & $\begin{array}{l}\beta+\beta+ \\
\beta 0 \beta+ \\
\beta 0 \beta 0\end{array}$ & $\begin{array}{c}4 \\
10 \\
6\end{array}$ & $\begin{array}{c}5.9 \\
14.8 \\
8.8\end{array}$ \\
\hline
\end{tabular}

HGVS = Human Genome Variation Society; $\mathrm{N}$ = number.

Each allele belonging to genotype was classified according to the corresponding phenotypic expression $(\beta+$ or $\beta 0$ ) and patients were divided into three groups: homozygous $\beta+(\mathrm{N}=19 ; 27.9 \%)$, compound heterozygous $\beta 0 \beta+(\mathrm{N}=24 ; 35.3 \%)$, and homozygous $\beta 0$ $(\mathrm{N}=25 ; 36.8 \%)$.

\subsection{Genotype and Clinical Correlates}

The clinically relevant findings in the three groups are summarized in Table 2. Age, gender, frequency of splenectomy, mean pre-transfusion hemoglobin and serum ferritin levels were comparable among the groups. Age at the start of regular transfusions and chelation therapy tended to be lower in the homozygous $\beta 0$ group, but the difference was not significant.

Table 2. Demographic, transfusion, chelation and clinical characteristics in the three groups identified on the basis of the $\beta$-globin gene phenotypic expression.

\begin{tabular}{|c|c|c|c|c|}
\hline & $\begin{array}{c}\beta+\beta+ \\
(N=19)\end{array}$ & $\begin{array}{c}\beta 0 \beta+ \\
(\mathrm{N}=24)\end{array}$ & $\begin{array}{c}\beta 0 \beta 0 \\
(\mathrm{~N}=25)\end{array}$ & $p$ \\
\hline Age (years) & $12.45 \pm 3.69$ & $13.13 \pm 3.30$ & $10.53 \pm 3.65$ & 0.071 \\
\hline Males/Females & $10 / 9$ & $13 / 11$ & $10 / 15$ & 0.559 \\
\hline Age at start of regular transfusion (months) & $20.46 \pm 29.78$ & $19.74 \pm 17.69$ & $12.44 \pm 11.83$ & 0.339 \\
\hline Chelation starting age (years) & $4.92 \pm 5.62$ & $3.41 \pm 2.24$ & $2.94 \pm 0.93$ & 0.958 \\
\hline Splenectomy, N (\%) & $1(5.3)$ & $3(12.5)$ & $3(12.0)$ & 0.696 \\
\hline Positive HCV RNA (\%) & $0(0.0)$ & $0(0.0)$ & $1(4.0)$ & 0.418 \\
\hline $\begin{array}{c}\text { Chelation therapy, N (\%) } \\
\text { DFO } \\
\text { DFP } \\
\text { DFX } \\
\text { Combined DFO + DFP } \\
\text { Sequential DFO/DFP } \\
\text { Combined DFP + DFX }\end{array}$ & $\begin{array}{c}2(10.5) \\
4(21.1) \\
12(63.2) \\
0(0.0) \\
0(0.0) \\
1(5.3)\end{array}$ & $\begin{array}{c}0(0.0) \\
3(12.5) \\
18(75.0) \\
1(4.2) \\
1(4.2) \\
1(4.2)\end{array}$ & $\begin{array}{c}0(0.0) \\
2(8.0) \\
21(84.0) \\
2(8.0) \\
0(0.0) \\
0(0.0)\end{array}$ & 0.299 \\
\hline $\begin{array}{c}\text { Compliance, N (\%) } \\
\text { optimal } \\
\text { good } \\
\text { insufficient }\end{array}$ & $\begin{array}{c}10(52.6) \\
8(42.1) \\
1(5.3)\end{array}$ & $\begin{array}{c}10(41.7) \\
12(50.0) \\
2(8.3)\end{array}$ & $\begin{array}{c}11(44.0) \\
11(44.0) \\
3(12.0)\end{array}$ & 0.905 \\
\hline Pre-transfusion hemoglobin $(\mathrm{g} / \mathrm{dL})$ & $9.93 \pm 0.46$ & $9.52 \pm 0.51$ & $9.59 \pm 0.58$ & 0.072 \\
\hline Ferritin levels (ng/L) & $1684.14 \pm 1276.53$ & $1655.56 \pm 1518.69$ & $1886.17 \pm 1805.39$ & 0.901 \\
\hline
\end{tabular}


The number of transfusional units in the 12 months before the MRI scan was available for 14 patients with homozygous $\beta+$ genotype (mean value: $31.79 \pm 11.13$ ), 18 patients with heterozygous $\beta 0 \beta+$ genotype (mean value: $37.18 \pm 10.40$ ), and 17 patients with homozygous $\beta 0$ genotype (mean value: $38.89 \pm 12.79$ ) and, besides the trend, no association with the genotype was detected $(p=0.258)$.

No difference was found in the distribution of the different chelation regimens or in the compliance.

\subsection{Genotype and MRI Findings}

Mean MRI LIC was $7.19 \pm 8.79 \mathrm{mg} / \mathrm{g} \mathrm{dw}$ and hepatic iron overload was detected in $44(64.7 \%)$ patients. In the 71 patients in whom pancreatic T2* images were available, mean global pancreas T2* value was $19.82 \pm 11.54 \mathrm{~ms}$, and pancreatic iron overload had an incidence of $73.1 \%$. Mean global heart T2* value was $33.75 \pm 10.49 \mathrm{~ms}$. All seven $(10.3 \%)$ patients with myocardial iron overload had both hepatic and pancreatic iron overload.

Mean serum ferritin levels were directly correlated with MRI LIC values $(\mathrm{R}=0.715$; $p<0.0001)$ and inversely correlated with global pancreas $\mathrm{T} 2 *$ values $(\mathrm{R}=-0.442 ; p=0.001)$ and global heart $\mathrm{T} 2 *$ values $(\mathrm{R}=-0.512 ; p<0.0001)$. No association between iron overload in the different organs and age at start of regular transfusions or chelation was detected.

MRI LIC values were inversely correlated with global pancreas $T 2 *$ values $(R=-0.561$; $p<0.0001)$, as well as global heart T2* values $(\mathrm{R}=-0.595 ; p<0.0001)$, and a positive correlation was detected between global pancreas and heart $\mathrm{T} 2 *$ values $(\mathrm{R}=0.609 ; p<0.0001)$.

Table 3 summarizes the MRI findings in the three groups. MRI LIC values were comparable among the three groups.

Table 3. MRI findings in the three groups identified on the basis of the $\beta$-globin gene phenotypic expression.

\begin{tabular}{|c|c|c|c|c|}
\hline & $\begin{array}{c}\beta+\beta+ \\
(\mathbf{N}=19)\end{array}$ & $\begin{array}{c}\beta 0 \beta+ \\
(\mathrm{N}=24)\end{array}$ & $\begin{array}{c}\beta 0 \beta 0 \\
(N=25)\end{array}$ & $p$ \\
\hline MRI LIC (mg/g dw) & $5.39 \pm 5.59$ & $6.67 \pm 10.29$ & $9.07 \pm 9.19$ & 0.140 \\
\hline MRI LIC > 3 mg/g dw, N (\%) & $12(63.2)$ & $13(54.2)$ & $18(72.0)$ & 0.433 \\
\hline Global pancreas $\mathrm{T} 2 *(\mathrm{~ms})$ & $24.80 \pm 12.95$ & $21.60 \pm 8.89$ & $14.38 \pm 10.68$ & 0.006 \\
\hline Global pancreas T2* < $26 \mathrm{~ms}, \mathrm{~N}(\%)$ & $8(42.1)$ & $19 / 23(82.6)$ & $22(88.0)$ & 0.001 \\
\hline Global heart $\mathrm{T}^{*}(\mathrm{~ms})$ & $36.93 \pm 7.78$ & $35.53 \pm 9.17$ & $29.61 \pm 12.35$ & 0.042 \\
\hline Global heart T2* < 20 ms, N (\%) & $1(5.3)$ & $2(8.3)$ & $4(16.0)$ & 0.472 \\
\hline Left atrial area $\left(\mathrm{cm}^{2} / \mathrm{m}^{2}\right)$ & $12.54 \pm 1.21$ & $12.65 \pm 1.96$ & $13.49 \pm 3.97$ & 0.881 \\
\hline Right atrial area $\left(\mathrm{cm}^{2} / \mathrm{m}^{2}\right)$ & $11.97 \pm 2.51$ & $11.53 \pm 1.29$ & $12.29 \pm 3.98$ & 0.964 \\
\hline $\operatorname{LV} \operatorname{EDVI}\left(\mathrm{mL} / \mathrm{m}^{2}\right)$ & $80.84 \pm 12.82$ & $80.65 \pm 12.89$ & $79.87 \pm 15.02$ & 0.874 \\
\hline $\operatorname{LV}$ ESVI $\left(\mathrm{mL} / \mathrm{m}^{2}\right)$ & $34.26 \pm 11.85$ & $31.57 \pm 6.85$ & $29.23 \pm 7.69$ & 0.238 \\
\hline LV SVI $\left(\mathrm{mL} / \mathrm{m}^{2}\right)$ & $49.05 \pm 8.92$ & $50.80 \pm 9.14$ & $49.73 \pm 8.22$ & 0.899 \\
\hline LV mass index $\left(\mathrm{g} / \mathrm{m}^{2}\right)$ & $51.02 \pm 13.66$ & $52.00 \pm 12.95$ & $51.23 \pm 10.38$ & 0.963 \\
\hline LV EF (\%) & $60.62 \pm 6.69$ & $61.87 \pm 4.39$ & $62.99 \pm 4.31$ & 0.334 \\
\hline $\mathrm{LV}$ cardiac index $\left(\mathrm{L} / \mathrm{min} / \mathrm{m}^{2}\right)$ & $4.35 \pm 0.81$ & $4.02 \pm 1.04$ & $4.24 \pm 0.75$ & 0.484 \\
\hline $\operatorname{RV} \operatorname{EDVI}\left(\mathrm{mL} / \mathrm{m}^{2}\right)$ & $82.41 \pm 12.52$ & $80.48 \pm 15.49$ & $76.36 \pm 14.23$ & 0.390 \\
\hline $\operatorname{RV} \operatorname{ESVI}\left(\mathrm{mL} / \mathrm{m}^{2}\right)$ & $32.98 \pm 7.99$ & $30.57 \pm 6.78$ & $27.64 \pm 6.28$ & 0.062 \\
\hline $\operatorname{RV~SVI~}\left(\mathrm{mL} / \mathrm{m}^{2}\right)$ & $49.80 \pm 9.89$ & $49.78 \pm 10.67$ & $49.72 \pm 8.91$ & 0.950 \\
\hline RV EF (\%) & $60.27 \pm 7.83$ & $61.35 \pm 5.29$ & $63.57 \pm 3.50$ & 0.181 \\
\hline Replacement myocardial fibrosis, N (\%) & $0 / 1(0.0)$ & $1 / 5(20.0)$ & $0 / 5(16.7)$ & 0.517 \\
\hline
\end{tabular}

$\mathrm{N}=$ number; MRI = magnetic resonance imaging; $\mathrm{LIC}=$ liver iron concentration; $\mathrm{LV}=$ left ventricular; EDVI = enddiastolic volume index; ESVI = end-systolic volume index; SVI = stroke volume index; LV = ejection fraction; $\mathrm{RV}=$ right ventricular.

Global pancreas T2* values were significantly lower in the homozygous $\beta 0$ group than in the homozygous $\beta+$ group $(p=0.024)$ (Figure 1A). The percentage of patients 
with global pancreas $\mathrm{T}^{*}<26 \mathrm{~ms}$ was significantly higher in both heterozygous $\beta 0 \beta+$ and homozygous $\beta 0$ groups than in the homozygous $\beta+$ group $(p=0.018$ and $p=0.003$, respectively) (Figure 1B). The OR for abnormal global pancreas T2* values was 6.53 (1.59$26.7995 \% \mathrm{CI} ; p=0.009)$ for patients with the heterozygous $\beta 0 \beta+$ genotype and 10.08 $(2.22-45.71 \% \mathrm{CI} ; p=0.003)$ for patients with the homozygous $\beta 0$ genotype versus patients with the homozygous $\beta+$ genotype.


Figure 1. (A) Mean global pancreas T2* values in the three groups identified based on the $\beta$-globin gene phenotypic expression. (B) Frequency of patients with global pancreas $\mathrm{T} 2^{*}<26 \mathrm{~ms}$ in the three phenotypic groups. The $p$-value for each significant pairwise comparison is indicated.

The homozygous $\beta 0$ group showed significantly lower global heart $\mathrm{T} 2 *$ values than the homozygous $\beta+$ group $(p=0.048)$ (Figure 2$)$. In homozygous $\beta 0$ patients, the frequency of myocardial iron overload was about three times higher than in patients with homozygous $\beta+$ genotype and two times higher than in patients with $\beta 0 \beta+$, but this difference was not significant.

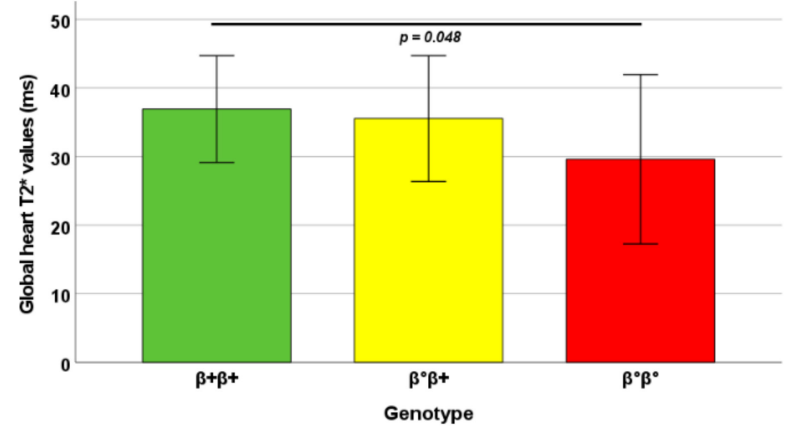

Figure 2. Mean global heart $\mathrm{T} 2 *$ values in the three groups identified based on the $\beta$-globin gene phenotypic expression. The $p$-value for each significant pairwise comparison is indicated.

Biventricular function parameters were assessed in 63 patients, because for five patients a short MRI protocol was chosen to avoid sedation. There were not significant 
differences among groups in bi-atrial areas, biventricular volume indexes and ejection fractions, and LV mass index.

Eleven patients completed the MRI protocol with acquisition of the LGE images and only one of them showed replacement myocardial fibrosis.

\subsection{Genotype and Complications}

No patient had liver fibrosis or cirrhosis.

Diabetes mellitus was not diagnosed in any patient. Hypogonadism, hypothyroidism, and $\mathrm{GH}$ deficit developed in $5.9 \%$ of patients and prevalence of hypoparathyroidism was $4.4 \%$. At least one endocrine complication was detected in $13(19.1 \%)$ patients. Frequency of hypogonadism, hypothyroidism, hypoparathyroidism, GH deficit, and endocrinopathies globally considered was comparable among the three groups (Table 4).

Table 4. Hepatic, endocrine and cardiac complications in the three groups identified on the basis of the $\beta$-globin gene phenotypic expression.

\begin{tabular}{|c|c|c|c|c|}
\hline & $\begin{array}{c}\beta+\beta+ \\
(N=19)\end{array}$ & $\begin{array}{c}\beta 0 \beta+ \\
(\mathrm{N}=24)\end{array}$ & $\begin{array}{c}\beta 0 \beta 0 \\
(N=25)\end{array}$ & $p$ \\
\hline Liver fibrosis or cirrhosis, $\mathrm{N}(\%)$ & $0(0.0)$ & $0(0.0)$ & $0(0.0)$ & - \\
\hline Diabetes mellitus, N (\%) & $0(0.0)$ & $0(0.0)$ & $0(0.0)$ & - \\
\hline Hypogonadism, N (\%) & $0(0.0)$ & $2(8.3)$ & $2(8.0)$ & 0.438 \\
\hline Hypothyroidism, N (\%) & $1(5.3)$ & $2(8.3)$ & $1(4.0)$ & 0.805 \\
\hline Hypoparathyroidism, N (\%) & $0(0.0)$ & $2(8.3)$ & $1(4.0)$ & 0.414 \\
\hline GH deficit, N (\%) & $1(5.3)$ & $1(4.2)$ & $2(8.0)$ & 0.842 \\
\hline At least one endocrinopathy, N (\%) & $2(10.5)$ & $6(25.0)$ & $5(20.0)$ & 0.483 \\
\hline Heart failure, N (\%) & $0(0.0)$ & $0(0.0)$ & $0(0.0)$ & - \\
\hline Arrhythmias, N (\%) & $0(0.0)$ & $0(0.0)$ & $1(4.0)$ & 0.418 \\
\hline
\end{tabular}

$\mathrm{N}=$ number; $\mathrm{GH}$ = growth hormone.

No patient had heart failure. One patient had an ectopic atrial tachycardia which resulted in left ventricular dysfunction and required hospitalization and treatment with anti-arrhythmic drugs. This patient was a nine-year-old male with a homozygous $\beta 0$ genotype and elevated iron levels (MRI LIC $=9.05 \mathrm{mg} / \mathrm{g} \mathrm{dw}$, global pancreas $\mathrm{T}^{*}=4.20 \mathrm{~ms}$, and global heart $\left.\mathrm{T}^{*}=2.40 \mathrm{~ms}\right)$.

\section{Discussion}

The knowledge of the molecular background of $\beta$-thalassemia can play a key role in the understanding of the factors affecting the diverse clinical manifestations. In the present study, we evaluated the impact of an underlying genetic defect on the development of disease complications in children with TDT. To the best of our knowledge, few studies, involving mainly patients from a limited area of Egypt, have explored this issue $[14,16]$. The children represent an ideal study population, due to the absence of the "aging" effect, with age "per $\mathrm{se}^{\prime \prime}$ being a powerful risk factor for the development of several complications $[45,46]$.

We analyzed a representative sample of the Italian pediatric population with TDT, in which 33 different genotypes were identified. In line with previous studies on adult Italian patients [15,47], the most common mutations were CD39 and IVS-1,110. In the Egyptian studies, the commonest mutations were IVS-1,1, IVS-1,110, and IVS-1,6 [16].

Patients were divided into three groups according to their genotype: homozygous $\beta 0$, with two severe mutations and consequently a high alpha-non alpha globin chain imbalance, heterozygous $\beta 0 \beta+$, characterized by a combination of mild/severe mutations, and homozygous $\beta+$, with two mild mutations and a lower imbalance between alpha and beta globin chains.

The three groups were homogeneous for age, sex, and hemato-chemical parameters. The transfusion demand tended to be lower in the homozygous $\beta+$ group than in the other two groups, but the difference was not statistically significant, likely because the datum was 
not available for all patients and the transfusion burden may change from center to center, depending also on red blood cell preparation and concentration. Moreover, it has been suggested that other factors (i.e., the spleen status) could contribute, more accurately than the genotype, to provide a basal evaluation of residual erythropoietic activity, and therefore, of the blood consumption [48]. Other studies found a significant association between genotype and frequency of blood transfusions, since in $\beta 0$ homozygotes the complete absence of $\beta$-hemoglobin chains increases the degree of hemolysis and blood requests, also leading to a higher iron overload [16,49].

MRI LIC values tended to be higher in the homozygous $\beta 0$ group, but the difference among the group was not significant. Conversely, global heart T2* values were significantly lower in the homozygous $\beta^{\circ}$ group than in the homozygous $\beta+$ group. Liver and heart have not only different iron uptake mechanisms, resulting in a "delay" in cardiac iron overload, but also different rates of iron clearance [50]. The capacity of the chelation therapy to remove iron from the liver in a faster way than from the heart is a potential explanation of our finding. In contrast with our study, Hassan et al. found that the homozygous $\beta 0$ genotype was associated with significantly higher liver iron content compared to the heterozygous $\beta 0 \beta+$ and homozygous $\beta+$ genotypes [16]. These inconsistent results can be explained by differences in study populations. We considered only TDT patients, while $16.4 \%$ of their patients, all in the homozygous $\beta+$ group, had non-transfusion-dependent thalassemia (NTDT). Although iron overload can occur also in NTDT patients, due to the increased intestinal iron absorption, it occurs at a slower rate than in TDT patients [51]. Iron seems to be less adequately controlled in the Egyptian population in comparison to our patients, as highlighted by the higher mean serum ferritin levels (3385.8 vs. 1742.51 $\mathrm{ng} / \mathrm{mL}$ ) and mean MRI LIC values (17.4 vs. $7.19 \mathrm{mg} / \mathrm{g} \mathrm{dw}$ ). Moreover, the homozygous $\beta 0$ group had a significantly worse compliance than the other two groups [16], and treatment efficacy and success are highly dependent on patient compliance [52].

To the best of our knowledge, this is the first study to show an association between genotype and levels of pancreatic iron overload. Likely, this link was not masked by the effects of the iron chelation therapy, since it seems extremely hard to remove iron from the pancreas [53]. We found out that, compared to patients with the homozygous $\beta+$ genotype, patients with the homozygous $\beta 0$ genotype and patients with the $\beta 0 \beta+$ genotype had a risk ten and six times higher, respectively, to develop pancreatic iron overload. It could be hypothesized that the presence of at least one $\beta+$ allele, independently from the transfusional load, could be representative of a non-transfusion-dependent thalalassemialike phenotype, characterized by the tendency to limit extrahepatic iron distribution [54-57]. Surprisingly, besides the young age, more than $80 \%$ of our patients with at least one $\beta 0$ allele had pancreatic iron overload. Pancreatic iron is a powerful predictor for the alterations of glucose metabolism, although a latency time exists before pancreatic iron could cause impaired glucose tolerance and overt diabetes [53,58]. Moreover, pancreatic iron has a profound link with heart disease, being a good predictor for myocardial dysfunction in the absence of cardiac iron, for cardiac iron, for heart failure, and for arrhythmias [53,5961]. Accordingly, it seems paramount to incorporate the pancreatic $\mathrm{T}^{*}$ assessment in the evaluation and monitoring of young children with TDT, especially in the presence of a $\beta 0$ allele. Thalassemic children were shown to be prescribed a lower mean dose of chelating drug and a delayed dose increase in comparison with adult patients [62], but in the presence of pancreatic iron overload it would be prudent to modify or intensify the iron chelation therapy to prospectively ward off both alterations of glucose metabolism and cardiac iron accumulation.

We failed to detect a correlation between genotype and biventricular volumes and ejection fractions and LV mass index, likely because all patients had normal or near-normal values of these parameters.

In our study population, no patient had liver fibrosis or cirrhosis and only one patient had hepatitis $\mathrm{C}$ virus (HCV) infection, confirming that in Italy the implemented measures to improve blood transfusion screening have significantly reduced the risk of getting an 
infection. Indeed, in an Italian study involving 1079 TDT patients with a mean age of 37.79 \pm 10.11 years, only $37.1 \%$ had never contracted the HCV infection [53]. In the same study, the prevalence of diabetes mellitus was $17.5 \%$. Conversely, none of our pediatric patient showed diabetes mellitus. In thalassemia, diabetes is a late complication, and its prevalence is significantly associated with the age of the patient [63-65].

The prevalence of the other endocrine complications in our pediatric population was hypogonadism, hypothyroidism and GH deficit- 5.9\%, and hypoparathyroidism-4.4\%. This prevalence was consistent with some studies $[66,67]$, while other studies reported a significantly higher incidence of endocrinopathies [14,16]. These discrepancies could be attributed to differences in age distribution and therapeutic management, and to genetic, geographical, cultural, and economic factors. In pediatric as well as in adult thalassemia patients, the $\beta 0 \beta 0$ genotype was previously demonstrated to be associated with a higher rate of endocrinopathies $[14,16,49,63,68]$, likely due to a greater rate of iron loading through higher red cell consumption and a higher vulnerability to free radical damage. It is highly probably that, in the present study, this association is hidden by the low number of patients with endocrinopathies.

We were not able to explore the association between genotype and cardiac complications, since no patient had heart failure and only a single patient had arrythmias. Of note, this patient had a homozygous $\beta 0$ genotype, which, in a prospective multicenter study, emerged as a risk factor for the development of cardiac arrhythmias and complications globally considered [69].

The main limitation of this study is the small sample size. Moreover, the previous complete transfusion history and chelation therapy, as potential determinants of the described pattern of iron organ distribution, were not available.

\section{Conclusions}

In pediatric TDT patients there is an association between genotype and cardiac and pancreatic iron overload. Patients with homozygous $\beta+$ genotype had significantly lower myocardial iron levels than $\beta 0 \beta 0$ patients and significantly lower pancreatic iron levels than $\beta 0 \beta+$ and $\beta 0 \beta 0$ patients. So, the knowledge of the genotype can be valuable in predicting some patients' phenotypic features and in helping the clinical and instrumental management of TDT patients.

Author Contributions: A.M. conceived the study, performed the statistical analysis, and drafted the initial manuscript. L.P. was responsible for data collection and curation. P.R., M.C.P., M.R.G., L.C., G.M., F.M., E.F., R.R., S.R. and G.P. collected the data. V.P. assisted with the methods. F.C. supervised the study. All authors assisted with interpretation, commented on drafts of the manuscript, and approved the final version. All authors have read and agreed to the published version of the manuscript.

Funding: The E-MIOT project, which is operated through Fondazione Toscana Gabriele Monasterio in Pisa, receives "no-profit support" from industry sponsorships (Chiesi Farmaceutici S.p.A. and Bayer S.p.A.). The funders had no role in study design, data collection and analysis, decision to publish, or preparation of the manuscript.

Institutional Review Board Statement: The study was conducted according to the guidelines of the Declaration of Helsinki, and approved by the Institutional Ethics Committee of Area Vasta Nord Ovest (protocol code 56664, date of approval: 8 October 2015).

Informed Consent Statement: Informed consent was obtained from all parents of patients participating in the study.

Data Availability Statement: The data presented in this study are available on request from the corresponding author. The data are not publicly available due to privacy.

Acknowledgments: We would like to thank all the colleagues involved in the E-MIOT project (https: / / emiot.ftgm.it/ accessed on 26 January 2022). We thank Silvia Miconi for her skillful secretarial work and all patients and the Italian Thalassemia Foundation "L. Giambrone" for their cooperation. 
Conflicts of Interest: The authors declare no conflict of interest.

\section{References}

1. Cao, A.; Galanello, R. Beta-thalassemia. Genet. Med. 2010, 12, 61-76. [CrossRef] [PubMed]

2. Thein, S.L. Genetic modifiers of beta-thalassemia. Haematologica 2005, 90, 649-660. [PubMed]

3. Weatherall, D.J. The inherited diseases of hemoglobin are an emerging global health burden. Blood 2010, 115, 4331-4336. [CrossRef] [PubMed]

4. Schrier, S.L. Pathophysiology of thalassemia. Cur.r Opin. Hematol. 2002, 9, 123-126. [CrossRef] [PubMed]

5. Cappellini, M.D.; Cohen, A.; Porter, J.; Taher, A.; Viprakasit, V. Guidelines for the Management of Transfusion Dependent Thalassaemia (TDT), 3rd ed.; Thalassaemia International Federation: Nicosia, Cyprus, 2014.

6. Andrews, P.A. Disorders of iron metabolism. N. Engl. J. Med. 2000, 342, 1293; author reply 1294. [PubMed]

7. Ozment, C.P.; Turi, J.L. Iron overload following red blood cell transfusion and its impact on disease severity. Biochim. Biophys. Acta 2009, 1790, 694-701. [CrossRef] [PubMed]

8. Hentze, M.W.; Muckenthaler, M.U.; Andrews, N.C. Balancing acts: Molecular control of mammalian iron metabolism. Cell 2004, 117, 285-297. [CrossRef]

9. Borgna-Pignatti, C.; Rugolotto, S.; De Stefano, P.; Zhao, H.; Cappellini, M.D.; Del Vecchio, G.C.; Romeo, M.A.; Forni, G.L.; Gamberini, M.R.; Ghilardi, R.; et al. Survival and complications in patients with thalassemia major treated with transfusion and deferoxamine. Haematologica 2004, 89, 1187-1193. [PubMed]

10. Argyropoulou, M.I.; Kiortsis, D.N.; Astrakas, L.; Metafratzi, Z.; Chalissos, N.; Efremidis, S.C. Liver, bone marrow, pancreas and pituitary gland iron overload in young and adult thalassemic patients: A T2 relaxometry study. Eur. Radiol. 2007, 17, 3025-3030. [CrossRef] [PubMed]

11. Pepe, A.; Meloni, A.; Rossi, G.; Cuccia, L.; D’Ascola, G.D.; Santodirocco, M.; Cianciulli, P.; Caruso, V.; Romeo, M.A.; Filosa, A.; et al. Cardiac and hepatic iron and ejection fraction in thalassemia major: Multicentre prospective comparison of combined deferiprone and deferoxamine therapy against deferiprone or deferoxamine monotherapy. J. Cardiovasc. Magn. Reson. $2013,15,1$. [CrossRef] [PubMed]

12. Modell, B.; Khan, M.; Darlison, M.; Westwood, M.A.; Ingram, D.; Pennell, D.J. Improved survival of thalassaemia major in the UK and relation to T2* cardiovascular magnetic resonance. J. Cardiovasc. Magn. Reson. 2008, 10, 42. [CrossRef]

13. Pepe, A.; Pistoia, L.; Gamberini, M.R.; Cuccia, L.; Lisi, R.; Cecinati, V.; Maggio, A.; Sorrentino, F.; Filosa, A.; Rosso, R.; et al. National networking in rare diseases and reduction of cardiac burden in thalassemia major. Eur. Heart J. 2021. [CrossRef] [PubMed]

14. Al-Akhras, A.; Badr, M.; El-Safy, U.; Kohne, E.; Hassan, T.; Abdelrahman, H.; Mourad, M.; Brintrup, J.; Zakaria, M. Impact of genotype on endocrinal complications in beta-thalassemia patients. Biomed. Rep. 2016, 4, 728-736. [CrossRef] [PubMed]

15. Pistoia, L.; Meloni, A.; Salvadori, S.; Spasiano, A.; Lisi, R.; Rosso, R.; Maggio, A.; D’Ascola, D.G.; Cuccia, L.; Mangione, M.; et al. Cardiac involvement by CMR in different genotypic groups of thalassemia major patients. Blood Cells Mol. Dis. 2019, $77,1-7$. [CrossRef] [PubMed]

16. Hassan, T.H.; Salam, M.M.A.; Zakaria, M.; Shehab, M.; Sarhan, D.T.; Zidan, E.S.H.; El Gerby, K.M. Impact of Genotype of Beta Globin Gene on Hepatic and Myocardial Iron Content in Egyptian Patients with Beta Thalassemia. Indian J. Hematol. Blood Transfus. 2019, 35, 284-291. [CrossRef]

17. Ramazzotti, A.; Pepe, A.; Positano, V.; Rossi, G.; De Marchi, D.; Brizi, M.G.; Luciani, A.; Midiri, M.; Sallustio, G.; Valeri, G.; et al. Multicenter validation of the magnetic resonance $2^{*}$ technique for segmental and global quantification of myocardial iron. $J$. Magn. Reson. Imaging 2009, 30, 62-68. [CrossRef]

18. Meloni, A.; De Marchi, D.; Pistoia, L.; Grassedonio, E.; Peritore, G.; Preziosi, P.; Restaino, G.; Righi, R.; Riva, A.; Renne, S.; et al. Multicenter validation of the magnetic resonance T2* technique for quantification of pancreatic iron. Eur. Radiol. 2019, 29, 2246-2252. [CrossRef] [PubMed]

19. Meloni, A.; Ramazzotti, A.; Positano, V.; Salvatori, C.; Mangione, M.; Marcheschi, P.; Favilli, B.; De Marchi, D.; Prato, S.; Pepe, A.; et al. Evaluation of a web-based network for reproducible T2* MRI assessment of iron overload in thalassemia. Int. J. Med. Inf. 2009, 78, 503-512. [CrossRef] [PubMed]

20. Positano, V.; Salani, B.; Pepe, A.; Santarelli, M.F.; De Marchi, D.; Ramazzotti, A.; Favilli, B.; Cracolici, E.; Midiri, M.; Cianciulli, P.; et al. Improved T2* assessment in liver iron overload by magnetic resonance imaging. Magn. Reson. Imaging 2009, 27, $188-197$. [CrossRef] [PubMed]

21. Restaino, G.; Meloni, A.; Positano, V.; Missere, M.; Rossi, G.; Calandriello, L.; Keilberg, P.; Mattioni, O.; Maggio, A.; Lombardi, M.; et al. Regional and global pancreatic T*(2) MRI for iron overload assessment in a large cohort of healthy subjects: Normal values and correlation with age and gender. Magn. Reson. Med. 2011, 65, 764-769. [CrossRef] [PubMed]

22. Meloni, A.; Positano, V.; Ruffo, G.B.; Spasiano, A.; D’Ascola, D.G.; Peluso, A.; Keilberg, P.; Restaino, G.; Valeri, G.; Renne, S.; et al. Improvement of heart iron with preserved patterns of iron store by CMR-guided chelation therapy. Eur. Heart J. Cardiovasc. Imaging 2015, 16, 325-334. [CrossRef] [PubMed]

23. Meloni, A.; Positano, V.; Pepe, A.; Rossi, G.; Dell'Amico, M.; Salvatori, C.; Keilberg, P.; Filosa, A.; Sallustio, G.; Midiri, M.; et al. Preferential patterns of myocardial iron overload by multislice multiecho $\mathrm{T}^{*} 2 \mathrm{CMR}$ in thalassemia major patients. Magn. Reson. Med. 2010, 64, 211-219. [CrossRef] [PubMed] 
24. Positano, V.; Pepe, A.; Santarelli, M.F.; Scattini, B.; De Marchi, D.; Ramazzotti, A.; Forni, G.; Borgna-Pignatti, C.; Lai, M.E.; Midiri, M.; et al. Standardized T2* map of normal human heart in vivo to correct T2* segmental artefacts. NMR Biomed. 2007, 20, 578-590. [CrossRef]

25. Meloni, A.; Luciani, A.; Positano, V.; De Marchi, D.; Valeri, G.; Restaino, G.; Cracolici, E.; Caruso, V.; Dell'amico, M.C.; Favilli, B.; et al. Single region of interest versus multislice T2* MRI approach for the quantification of hepatic iron overload. J. Magn. Reson. Imaging 2011, 33, 348-355. [CrossRef] [PubMed]

26. Meloni, A.; Rienhoff, H.Y., Jr.; Jones, A.; Pepe, A.; Lombardi, M.; Wood, J.C. The use of appropriate calibration curves corrects for systematic differences in liver R2* values measured using different software packages. Br. J. Haematol. 2013, 161, 888-891. [CrossRef] [PubMed]

27. Wood, J.C.; Enriquez, C.; Ghugre, N.; Tyzka, J.M.; Carson, S.; Nelson, M.D.; Coates, T.D. MRI R2 and R2* mapping accurately estimates hepatic iron concentration in transfusion-dependent thalassemia and sickle cell disease patients. Blood 2005, 106, 1460-1465. [CrossRef] [PubMed]

28. Meloni, A.; De Marchi, D.; Positano, V.; Neri, M.G.; Mangione, M.; Keilberg, P.; Lendini, M.; Cirotto, C.; Pepe, A. Accurate estimate of pancreatic T2* values: How to deal with fat infiltration. Abdom. Imaging 2015, 40, 3129-3136. [CrossRef] [PubMed]

29. Cerqueira, M.D.; Weissman, N.J.; Dilsizian, V.; Jacobs, A.K.; Kaul, S.; Laskey, W.K.; Pennell, D.J.; Rumberger, J.A.; Ryan, T.; Verani, M.S. Standardized myocardial segmentation and nomenclature for tomographic imaging of the heart: A statement for healthcare professionals from the Cardiac Imaging Committee of the Council on Clinical Cardiology of the American Heart Association. Circulation 2002, 105, 539-542.

30. Meloni, A.; Righi, R.; Missere, M.; Renne, S.; Schicchi, N.; Gamberini, M.R.; Cuccia, L.; Lisi, R.; Spasiano, A.; Roberti, M.G.; et al. Biventricular Reference Values by Body Surface Area, Age, and Gender in a Large Cohort of Well-Treated Thalassemia Major Patients without Heart Damage Using a Multiparametric CMR Approach. J. Magn. Reson. Imaging 2021, 53, 61-70. [CrossRef]

31. Marsella, M.; Borgna-Pignatti, C.; Meloni, A.; Caldarelli, V.; Dell'Amico, M.C.; Spasiano, A.; Pitrolo, L.; Cracolici, E.; Valeri, G.; Positano, V.; et al. Cardiac iron and cardiac disease in males and females with transfusion-dependent thalassemia major: A T2* magnetic resonance imaging study. Haematologica 2011, 96, 515-520. [CrossRef]

32. Meloni, A.; Favilli, B.; Positano, V.; Cianciulli, P.; Filosa, A.; Quarta, A.; D’Ascola, D.; Restaino, G.; Lombardi, M.; Pepe, A. Safety of cardiovascular magnetic resonance gadolinium chelates contrast agents in patients with hemoglobinopaties. Haematologica 2009, 94, 1625-1627. [CrossRef] [PubMed]

33. Pepe, A.; Meloni, A.; Borsellino, Z.; Cuccia, L.; Borgna-Pignatti, C.; Maggio, A.; Restaino, G.; Gagliardotto, F.; Caruso, V.; Spasiano, A.; et al. Myocardial fibrosis by late gadolinium enhancement cardiac magnetic resonance and hepatitis $\mathrm{C}$ virus infection in thalassemia major patients. J. Cardiovasc. Med. 2015, 16, 689-695. [CrossRef] [PubMed]

34. Miller, S.A.; Dykes, D.D.; Polesky, H.F. A simple salting out procedure for extracting DNA from human nucleated cells. Nucleic Acids Res. 1988, 16, 1215. [CrossRef] [PubMed]

35. Angelucci, E.; Brittenham, G.M.; McLaren, C.E.; Ripalti, M.; Baronciani, D.; Giardini, C.; Galimberti, M.; Polchi, P.; Lucarelli, G. Hepatic iron concentration and total body iron stores in thalassemia major. N. Engl. J. Med. 2000, 343, 327-331. [CrossRef] [PubMed]

36. Anderson, L.J.; Holden, S.; Davis, B.; Prescott, E.; Charrier, C.C.; Bunce, N.H.; Firmin, D.N.; Wonke, B.; Porter, J.; Walker, J.M.; et al. Cardiovascular T2-star (T2*) magnetic resonance for the early diagnosis of myocardial iron overload. Eur. Heart J. 2001, 22, 2171-2179. [CrossRef] [PubMed]

37. Carpenter, J.P.; He, T.; Kirk, P.; Roughton, M.; Anderson, L.J.; de Noronha, S.V.; Sheppard, M.N.; Porter, J.B.; Walker, J.M.; Wood, J.C.; et al. On T2* magnetic resonance and cardiac iron. Circulation 2011, 123, 1519-1528. [CrossRef] [PubMed]

38. De Sanctis, V.; Soliman, A.T.; Elsedfy, H.; Yaarubi, S.A.; Skordis, N.; Khater, D.; El Kholy, M.; Stoeva, I.; Fiscina, B.; Angastiniotis, M.; et al. The ICET-A Recommendations for the Diagnosis and Management of Disturbances of Glucose Homeostasis in Thalassemia Major Patients. Mediterr. J. Hematol. Infect. Dis. 2016, 8, e2016058. [CrossRef]

39. De Sanctis, V.; Soliman, A.T.; Elsedfy, H.; Skordis, N.; Kattamis, C.; Angastiniotis, M.; Karimi, M.; Yassin, M.A.; El Awwa, A.; Stoeva, I.; et al. Growth and endocrine disorders in thalassemia: The international network on endocrine complications in thalassemia (I-CET) position statement and guidelines. Indian J. Endocrinol. Metab. 2013, 17, 8-18. [CrossRef]

40. De Sanctis, V.; Soliman, A.T.; Canatan, D.; Yassin, M.A.; Daar, S.; Elsedfy, H.; Di Maio, S.; Raiola, G.; Corrons, J.V.; Kattamis, C. Thyroid Disorders in Homozygous beta-Thalassemia: Current Knowledge, Emerging Issues and Open Problems. Mediterr. J. Hematol. Infect. Dis. 2019, 11, e2019029. [CrossRef]

41. De Sanctis, V.; Soliman, A.; Fiscina, B. Hypoparathyroidism: From diagnosis to treatment. Curr. Opin. Endocrinol. Diabetes Obes. 2012, 19, 435-442. [CrossRef] [PubMed]

42. Soliman, A.; De Sanctis, V.; Elsedfy, H.; Yassin, M.; Skordis, N.; Karimi, M.; Sobti, P.; Raiola, G.; El Kholy, M. Growth hormone deficiency in adults with thalassemia: An overview and the I-CET recommendations. Georgian Med. News 2013, 222, 79-88.

43. Jessup, M.; Abraham, W.T.; Casey, D.E.; Feldman, A.M.; Francis, G.S.; Ganiats, T.G.; Konstam, M.A.; Mancini, D.M.; Rahko, P.S.; Silver, M.A.; et al. 2009 focused update: ACCF/AHA Guidelines for the Diagnosis and Management of Heart Failure in Adults: A report of the American College of Cardiology Foundation/American Heart Association Task Force on Practice Guidelines: Developed in collaboration with the International Society for Heart and Lung Transplantation. Circulation 2009, 119, $1977-2016$. [PubMed] 
44. Buxton, A.E.; Calkins, H.; Callans, D.J.; DiMarco, J.P.; Fisher, J.D.; Greene, H.L.; Haines, D.E.; Hayes, D.L.; Heidenreich, P.A.; Miller, J.M.; et al. ACC/AHA/HRS 2006 key data elements and definitions for electrophysiological studies and procedures: A report of the American College of Cardiology/American Heart Association Task Force on Clinical Data Standards (ACC/AHA/HRS Writing Committee to Develop Data Standards on Electrophysiology). Circulation 2006, 114, 2534-2570. [PubMed]

45. Taher, A.T.; Cappellini, M.D. How I manage medical complications of beta-thalassemia in adults. Blood 2018, $132,1781-1791$. [CrossRef] [PubMed]

46. Pepe, A.; Meloni, A.; Rossi, G.; Midiri, M.; Missere, M.; Valeri, G.; Sorrentino, F.; D' Ascola, D.G.; Spasiano, A.; Filosa, A.; et al. Prediction of cardiac complications for thalassemia major in the widespread cardiac magnetic resonance era: A prospective multicentre study by a multi-parametric approach. Eur. Heart J. Cardiovasc. Imaging 2018, 19, 299-309. [CrossRef] [PubMed]

47. Rigoli, L.; Meo, A.; Miceli, M.R.; Alessio, K.; Caruso, R.A.; La Rosa, M.A.; Salpietro, D.C.; Ricca, M.; Barberi, I. Molecular analysis of beta-thalassaemia patients in a high incidence area of southern Italy. Clin. Lab. Haematol. 2001, 23, 373-378. [CrossRef] [PubMed]

48. Ricchi, P.; Meloni, A.; Costantini, S.; Spasiano, A.; Cinque, P.; Gargiulo, B.; Pepe, A.; Filosa, A. Red blood cell consumption in a large cohort of patients with thalassaemia: A retrospective analysis of main predictors. Ann. Hematol. 2020, 99, 1209-1215. [CrossRef]

49. Skordis, N.; Michaelidou, M.; Savva, S.C.; Ioannou, Y.; Rousounides, A.; Kleanthous, M.; Skordos, G.; Christou, S. The impact of genotype on endocrine complications in thalassaemia major. Eur. J. Haematol. 2006, 77, 150-156. [CrossRef]

50. Noetzli, L.J.; Carson, S.M.; Nord, A.S.; Coates, T.D.; Wood, J.C. Longitudinal analysis of heart and liver iron in thalassemia major. Blood 2008, 112, 2973-2978. [CrossRef]

51. Taher, A.T.; Viprakasit, V.; Musallam, K.M.; Cappellini, M.D. Treating iron overload in patients with non-transfusion-dependent thalassemia. Am. J. Hematol. 2013, 88, 409-415. [CrossRef]

52. Vichinsky, E. Iron Overload and Iron Chelation Therapy in Pediatric Patients. Oral. Hist. Rev. 2009, 2, 64. [CrossRef]

53. Pepe, A.; Pistoia, L.; Gamberini, M.R.; Cuccia, L.; Peluso, A.; Messina, G.; Spasiano, A.; Allo, M.; Bisconte, M.G.; Putti, M.C.; et al. The Close Link of Pancreatic Iron with Glucose Metabolism and with Cardiac Complications in Thalassemia Major: A Large, Multicenter Observational Study. Diabetes Care 2020, 43, 2830-2839. [CrossRef] [PubMed]

54. Garbowski, M.W.; Evans, P.; Vlachodimitropoulou, E.; Hider, R.; Porter, J.B. Residual erythropoiesis protects against myocardial hemosiderosis in transfusion-dependent thalassemia by lowering labile plasma iron via transient generation of apotransferrin. Haematologica 2017, 102, 1640-1649. [CrossRef]

55. Ricchi, P.; Ammirabile, M.; Costantini, S.; Spasiano, A.; Di Matola, T.; Verna, R.; Pepe, A.; Cinque, P.; Saporito, C.; Filosa, A.; et al. Soluble form of transferrin receptor as a biomarker of overall morbidity in patients with non-transfusion-dependent thalassaemia: A cross-sectional study. Blood Transfus. 2016, 14, 538-540. [PubMed]

56. Ricchi, P.; Ammirabile, M.; Spasiano, A.; Costantini, S.; Di Matola, T.; Pepe, A.; Cinque, P.; Pagano, L.; Casale, M.; Filosa, A.; et al Extramedullary haematopoiesis correlates with genotype and absence of cardiac iron overload in polytransfused adults with thalassaemia. Blood Transfus. 2014, 12 (Suppl. S1), s124-s130.

57. Ricchi, P.; Meloni, A.; Spasiano, A.; Neri, M.G.; Gamberini, M.R.; Cuccia, L.; Caruso, V.; Gerardi, C.; D' Ascola, D.G.; Rosso, R.; et al. Extramedullary hematopoiesis is associated with lower cardiac iron loading in chronically transfused thalassemia patients. Am. J. Hematol. 2015, 90, 1008-1012. [CrossRef]

58. 5-Noetzli, L.J.; Mittelman, S.D.; Watanabe, R.M.; Coates, T.D.; Wood, J.C. Pancreatic iron and glucose dysregulation in thalassemia major. Am. J. Hematol. 2012, 87, 155-160. [CrossRef]

59. Noetzli, L.J.; Papudesi, J.; Coates, T.D.; Wood, J.C. Pancreatic iron loading predicts cardiac iron loading in thalassemia major. Blood 2009, 114, 4021-4026. [CrossRef]

60. Meloni, A.; Restaino, G.; Missere, M.; De Marchi, D.; Positano, V.; Valeri, G.; Giuseppe D’Ascola, D.; Peluso, A.; Caterina Putti, M.; Lendini, M.; et al. Pancreatic iron overload by T2* MRI in a large cohort of well treated thalassemia major patients: Can it tell us heart iron distribution and function? Am. J. Hematol. 2015, 90, E189-E190. [CrossRef] [PubMed]

61. Salama, K.; Abdelsalam, A.; Eldin, H.S.; Youness, E.; Selim, Y.; Salama, C.; Hassanein, G.; Samir, M.; Zekri, H. The relationships between pancreatic $\mathrm{T} 2 *$ values and pancreatic iron loading with cardiac dysfunctions, hepatic and cardiac iron siderosis among Egyptian children and young adults with beta-thalassaemia major and sickle cell disease: A cross-sectional study. F1000Research 2020, 9, 1108. [CrossRef]

62. Taher, A.; Elalfy, M.S.; Al Zir, K.; Daar, S.; Al Jefri, A.; Habr, D.; Kriemler-Krahn, U.; El-Ali, A.; Roubert, B.; El-Beshlawy, A. Importance of optimal dosing $>/=30 \mathrm{mg} / \mathrm{kg} / \mathrm{d}$ during deferasirox treatment: 2.7 -yr follow-up from the ESCALATOR study in patients with beta-thalassaemia. Eur. J. Haematol. 2011, 87, 355-365. [CrossRef] [PubMed]

63. Jensen, C.E.; Tuck, S.M.; Old, J.; Morris, R.W.; Yardumian, A.; De Sanctis, V.; Hoffbrand, A.V.; Wonke, B. Incidence of endocrine complications and clinical disease severity related to genotype analysis and iron overload in patients with beta-thalassaemia. Eur. J. Haematol. 1997, 59, 76-81. [CrossRef] [PubMed]

64. Toumba, M.; Sergis, A.; Kanaris, C.; Skordis, N. Endocrine complications in patients with Thalassaemia Major. Pediatr. Endocrinol. Rev. 2007, 5, 642-648. [PubMed]

65. Pepe, A.; Meloni, A.; Rossi, G.; Caruso, V.; Cuccia, L.; Spasiano, A.; Gerardi, C.; Zuccarelli, A.; D’Ascola, D.G.; Grimaldi, S.; et al. Cardiac complications and diabetes in thalassaemia major: A large historical multicentre study. Br. J. Haematol. 2013, 163, 520-527. [CrossRef] [PubMed] 
66. Mahmoud, R.A.; Khodeary, A.; Farhan, M.S. Detection of endocrine disorders in young children with multi-transfused thalassemia major. Ital. J. Pediatr. 2021, 47, 165. [CrossRef] [PubMed]

67. Bilgin, B.K.; Yozgat, A.K.; Isik, P.; Culha, V.; Kacar, D.; Kara, A.; Ozbek, N.Y.; Yarali, N. The effect of deferasirox on endocrine complications in children with thalassemia. Pediatr. Hematol. Oncol. 2020, 37, 455-464. [CrossRef] [PubMed]

68. Chern, J.P.; Lin, K.H.; Tsai, W.Y.; Wang, S.C.; Lu, M.Y.; Lin, D.T.; Lin, K.S.; Lo, S.H. Hypogonadotropic hypogonadism and hematologic phenotype in patients with transfusion-dependent beta-thalassemia. J. Pediatr. Hematol. Oncol. 2003, 25, 880-884. [CrossRef] [PubMed]

69. Pistoia, L.; Meloni, A.; Ricchi, P.; Filosa, A.; Lisi, R.; Maggio, A.; Rosso, R.; Messina, G.; Iacono, N.D.; Cuccia, L.; et al. Genotypic groups as risk factors for cardiac magnetic resonance abnormalities and complications in thalassemia major: A large, multicentre study. Blood Transfus. 2021, 19, 168-176. [CrossRef] [PubMed] 